\title{
Design of the Quality of Life in Motion (QLIM) study: a randomized controlled trial to evaluate the effectiveness and cost-effectiveness of a combined physical exercise and psychosocial training program to improve physical fitness in children with cancer
}

Katja I Braam ${ }^{1 *+}$, Elisabeth M van Dijk ${ }^{2+}$, Margreet A Veening ${ }^{1}$, Marc B Bierings ${ }^{3}$, Johannes HM Merks ${ }^{4}$, Martha A Grootenhuis ${ }^{5}$, Mai JM Chinapaw ${ }^{6}$, Gerben Sinnema ${ }^{7}$, Tim Takken $^{8}$, Jaap Huisman², Gertjan JL Kaspers ${ }^{1}$, Eline van Dulmen-den Broeder ${ }^{1}$

\begin{abstract}
Background: Childhood cancer and its treatment have considerable impact on a child's physical and mental wellbeing. Especially long-term administration of chemotherapy and/or radiotherapy impairs physical fitness both during and after therapy, when children often present with muscle weakness and/or low cardiorespiratory fitness. Physical exercise can improve these two elements of physical fitness, but the positive effects of physical exercise might be further increased when a child's wellbeing is simultaneously enhanced by psychosocial training. Feeling better may increase the willingness and motivation to engage in sports activities. Therefore, this multi-centre study evaluates the short and long-term changes in physical fitness of a child with a childhood malignancy, using a combined physical exercise and psychosocial intervention program, implemented during or shortly after treatment. Also examined is whether positive effects on physical fitness reduce inactivity-related adverse health problems, improve quality of life, and are cost-effective.
\end{abstract}

Methods: This multi-centre randomized controlled trial compares a combined physical and psychosocial intervention program for children with cancer, with care as usual (controls). Children with cancer (aged 8-18 years) treated with chemotherapy and/or radiotherapy, and who are no longer than 1 year post-treatment, are eligible for participation. A total of 100 children are being recruited from the paediatric oncology/haematology departments of three Dutch university medical centres. Patients are stratified according to pubertal stage (girls: age $\leq 10$ or $>10$ years; boys: $\leq 11$ or $>11$ years), type of malignancy (haematological or solid tumour), and moment of inclusion into the study (during or after treatment), and are randomly assigned to the intervention or control group.

Discussion: Childhood cancer patients undergoing long-term cancer therapy may benefit from a combined physical exercise and psychosocial intervention program since it may maintain or enhance their physical fitness and increase their quality of life. However, the feasibility, patient need, and effectiveness of such a program should be established before the program can be implemented as part of standard care.

Trial registration number: NTR1531 (The Netherlands National Trial Register)

\footnotetext{
* Correspondence: katja.braam@vumc.nl

+ Contributed equally

'VU University Medical Center, department of Paediatrics and Division of

Oncology-Haematology, Amsterdam, the Netherlands

Full list of author information is available at the end of the article
} 


\section{Background}

Advances in diagnosis and treatment of childhood cancer have dramatically increased long-term survival. Consequently, the number of childhood cancer survivors (CCS) is growing and it is now evident that the disease and its treatment can significantly impair long-term health [1]. Adverse effects of a paediatric malignancy and its treatment are both frequent and diverse, and may emerge years after the completion of therapy. One study reported that about $75 \%$ of CCS has at least one late adverse health effect after a median follow-up of 17 years [1]. Therefore, paediatric oncologists and others involved in the care of childhood cancer patients need to focus not only on survival, but also on the quality of survival.

Impaired physical fitness (e.g. reduced cardiorespiratory function and/or decreased muscle strength) has been reported both during and after childhood cancer treatment [2-6]. Since physical fitness represents the functional status of many body functions involved in the performance of daily physical activities and/or physical exercise, physical fitness is considered an important health marker. Physical inactivity with subsequent muscle atrophy and reduced strength is probably the most prominent cause of this reduced state of physical fitness [6-9]. Again, this low physical fitness may lead to fatigue, obesity and a poor skeletal and/or mental health [7,9-14]. In turn, these factors may further reduce physical activity and physical fitness making these health outcomes a self-perpetuating condition if the cycle is not reversed.

All of these health outcomes (separately or simultaneously) may negatively impact both short and longterm health and observed health-related quality of life (HrQOL) $[12,14]$. Therefore, prevention of inactivityrelated health problems by increasing physical fitness, both during and after treatment, is essential.

Rehabilitation programs in adult cancer patients, including physical exercise and psychosocial support, report positive effects on physical fitness and HrQOL $[15,16]$. However, such programs are not available for children with cancer. For them it may be even more important to maintain physical fitness and psychosocial health, since childhood cancer occurs in a crucial period of life. During childhood essential physiological and psychological changes take place, and the basis for adult behaviour, lifestyle and health status is established $[17,18]$. No or little participation in physical activity over a longer period of time may have significant implications for future physical activity performance, physical and psychosocial health outcomes, and ultimately HrQOL $[19,20]$.

Studies describing physical exercise and its effects on muscle strength and physical fitness during and after treatment of childhood cancer are scarce, are performed in small study groups, and/or do not include a psychosocial support program to increase wellbeing, self-belief and compliance with the intervention [21-24]. The available studies show that it is safe for childhood cancer patients to engage in exercise interventions. However, high drop-out rates occur in physical exercise studies among cancer patients, leading to low powered or unbalanced data $[25,26]$. This was seen, for example, in a Dutch study testing a 12-week exercise training program (combining aerobic and strength exercises) in 9 childhood acute lymphoblastic leukaemia survivors (aged 6-18 years), in continuous remission and at least 3 years after diagnosis [27]. The 5 drop-outs (44\%) and their parents found the 12-week sessions too demanding and/ or difficult to combine with school attendance and other activities [27]. In addition, it appeared that parental support and patient self-belief are important factors related to compliance.

Based on these experiences, for the present study the 12 -week exercise training program was modified. The revised intervention program now combines a more gradual increase of exercise intensity with a psychosocial intervention aimed to enhance patient wellbeing, patient self-belief and parental support. The short and longterm effectiveness of this combined physical and psychosocial intervention, implemented during or shortly after cancer treatment in a large group of childhood cancer survivors, is evaluated in a randomized controlled trial (RCT). In this study physical fitness is the primary outcome; also examined is whether positive effects on physical fitness reduce inactivity-related adverse health problems, improve HrQOL, and are cost-effective. The design of this RCT is described below.

\section{Methods}

This study is part of a larger program of the Dutch Cancer Society. This larger Alpe d'HuZes Cancer Rehabilitation Research Program (A-CaRe) consists of four RCTs evaluating exercise intervention in different groups of cancer patients; these four studies use similar methodologies and outcome measures. An overview of the A-CaRe program has been described elsewhere [28]. Quality of Life in Motion (QLIM) is the only cancer and sport study of A-CaRe in the childhood cancer population.

This RCT among children with cancer, compares the primary and secondary outcome measures of the study between an intervention and a care-as-usual control group. In addition, cost utility and cost effectiveness is evaluated.

The intervention training program of QLIM consists of two elements. First the physical intervention, a structured, individualized and supervised physical exercise program of moderate to high intensity. Secondly the psychosocial intervention, which is an individualized 
structured program to enhance socio-emotional functioning and coping with disease-related effects. Improved wellbeing is expected to increase willingness and motivation to engage in sports activities and, as a result, enhance the efficacy of the exercise program.

\section{Study sample}

Eligible participants are aged between 8 and 18 years at the time of inclusion into the study, diagnosed with any type of childhood malignancy, treated with chemotherapy and/or radiotherapy, and are still receiving treatment, or are no longer than 12 months off treatment. Patients requiring a bone marrow transplantation and/ or growth hormone therapy are excluded. In addition, patients who depend on a wheelchair, who are not able to 'ride a bike', read, write, self-reflect, and/or follow instructions are also excluded from this study.

\section{Recruitment and randomisation}

Hundred children are being recruited from the department of Paediatric Oncology and Haematology of the VU University Medical Center (VUmc) in Amsterdam, the Wilhelmina Children's Hospital UMC in Utrecht (WKZ/UMCU), and the Emma Children's Hospital/Academic Medical Center (EKZ/AMC) in Amsterdam. Patient inclusion starts after approval of the Medical Ethics Committee (number 2008/208). The patients and their parents individually receive written and verbal information about the study, an informed consent form, and an addressed return envelope (Figure 1). Written informed consent is obtained from the parents or legal guardian of each patient, and also separately from each patient aged 12 years and older.

Baseline measurements (performance tests and questionnaires) occur as soon as the clinical condition of the patient enables him/her to participate in and complete the intervention program. After these baseline measurements the patient is randomised to either the intervention or the control group after being stratified according to type of malignancy (haematological cancer or solid tumour), pubertal stage (girls: age $\leq 10$ or $>10$ years; boys: $\leq 11$ or $>11$ years), and moment of inclusion into the study (during or after treatment). For those patients randomised to the intervention group the QLIM intervention starts within 2 weeks after baseline measurements. The control group receives care as usual.

\section{The QLIM intervention}

The intervention arm of the study consists of a combined physical and a psychosocial intervention.

\section{Physical intervention}

Since childhood cancer and its treatment are associated with a loss of both aerobic capacity and muscle strength, the 12-week physical intervention includes a combination

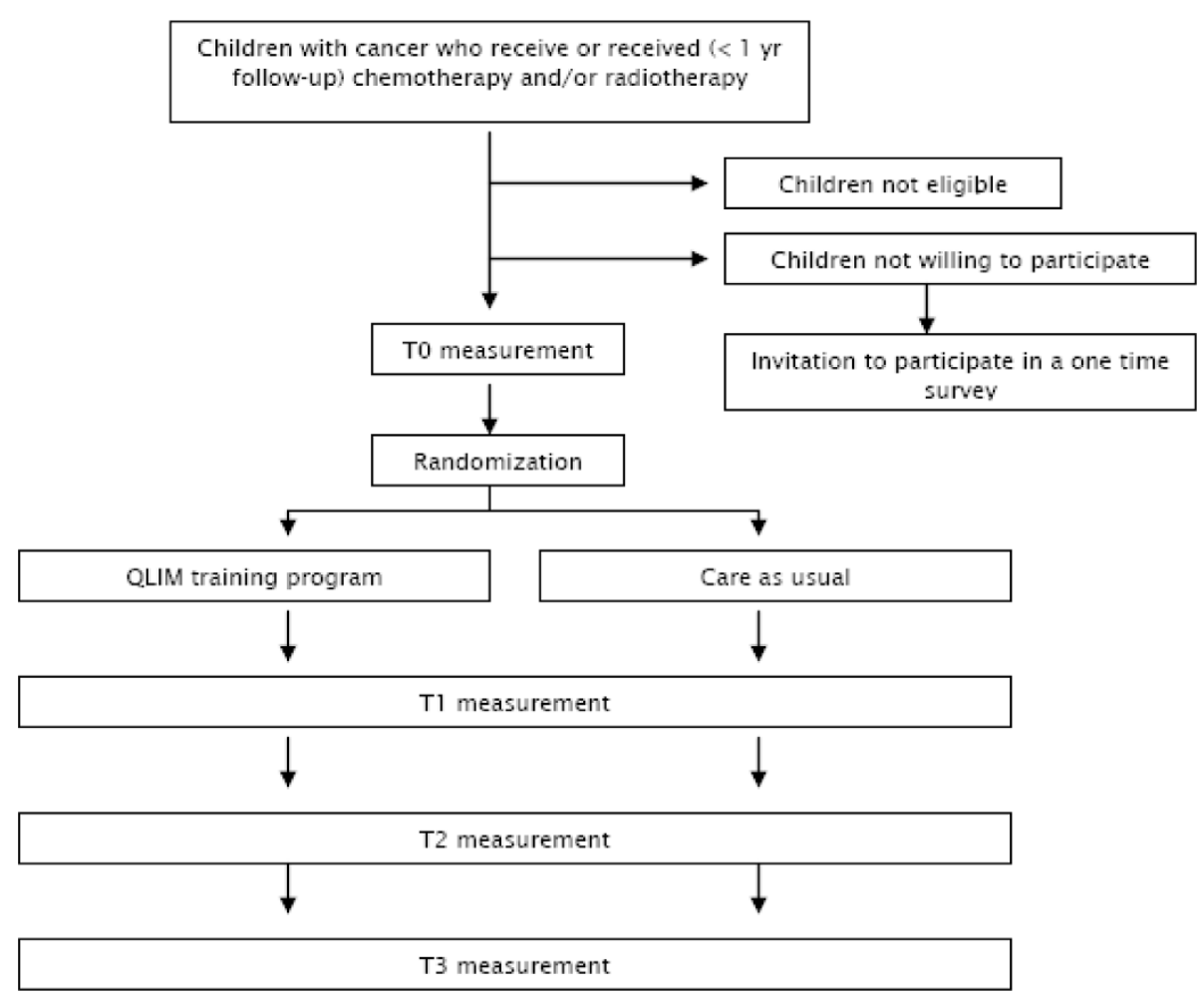

Figure 1 Flowchart of the Quality of Life in Motion (QLIM) study. 
of both cardiorespiratory and muscle strength training (twice a week for $45 \mathrm{~min}$ ) at a physical therapy sports centre near the child's home. Training is performed individually, under the supervision of an experienced paediatric physical therapist. Prior to the start of the intervention period all therapists receive the intervention protocol and personal instructions; during the intervention period a site visit is made to guarantee uniformity of the intervention between therapists.

The physical intervention consists of 3 phases of one month each (Figure 2). The primary goal of the $1^{\text {st }}$ phase is to increase muscle strength; the $2^{\text {nd }}$ phase aims to increase cardiorespiratory fitness; and the $3^{\text {rd }}$ phase aims to further increase both cardiorespiratory fitness and muscle strength through interval training. To improve compliance with the program, the sessions are of varying content. The intensity of the sessions gradually increases throughout the study. The intensity of the cardiopulmonary training is assessed by heart rate monitoring during the training session, whereas strength is assessed by the number of repetitions made per time period. Progression of physical fitness is monitored by field tests $[29,30]$ at the start and at the end of each phase by the therapists in the local sports centres. The aim of these field tests is to assess training progress for both the participant and their trainer.
In week 6 to 12, children are instructed to perform five additional exercises at home (at least twice a week). These exercises have an increasing intensity and frequency to enhance strength, flexibility and aerobic fitness [31]. This aims to further increase the training effects and to introduce physical exercise into their daily routine to encourage an active lifestyle after the intervention has ended. This home-based training is accompanied by music designed and timed for the duration of the exercises.

The performed level of activity, the number of repetitions achieved and the date are recorded in the physical training workbook. Patients randomised to the intervention group are also allowed to participate in additional sports activities and are stimulated to participate in school sports.

\section{Psychosocial intervention}

The psychosocial intervention is specifically developed for the QLIM study. The theoretical framework and exercises are based on clinical care for childhood cancer patients and on a cognitive-behavioural based group training that is used in clinical care for chronically ill children at the VUmc (not published). Regular cognitive-behavioural intervention techniques have been modified for this specific intervention program. The intervention is provided by a trained paediatric psychologist in the treatment centre of the child. An independent

\section{QLIM physical intervention}

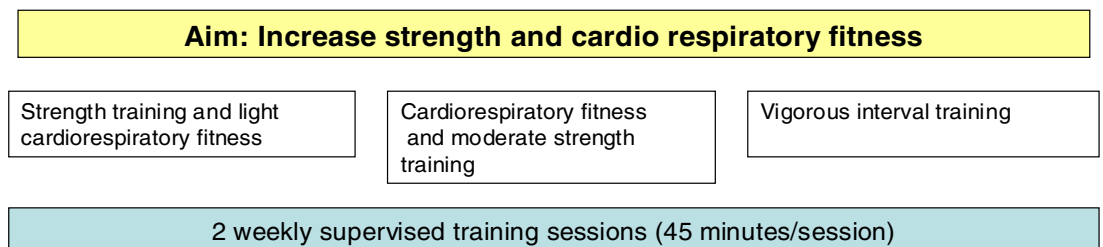

Minimal 2 weekly home-based exercise sessions

\begin{tabular}{|c|c|c|c|c|}
\hline Week 1-4 & Week 5-8 & \multicolumn{3}{|c|}{ Week 9-12 } \\
\hline Phase 1 & Phase 2 & & Phase 3 & \\
\hline $\begin{array}{l}\text { Exercise intensity } \\
66-77 \% \text { of HRmax }\end{array}$ & $\begin{array}{l}\text { Exercise intensity } \\
77-90 \% \text { of HRmax }\end{array}$ & & $\begin{array}{l}\text { Exercise intensity } \\
>90 \% \text { of HRmax }\end{array}$ & \\
\hline $\mathrm{FT}^{\#}$ & & FT & & FT \\
\hline
\end{tabular}

Figure 2 Details of the Quality of Life in Motion (QLIM) physical intervention. HFmax, maximum heart rate. \# FT, Field Tests: Modified Shuttle Walk Test; Steep Ramp Test; $10 \times 5$ meter sprint test; 30 second repetition maximum for sit-ups, push-ups, head and leg raises; 60second repetition maximum for squats. 
psychologist checks the quality and similarity between therapists in random site visits to the QLIM sessions.

The psychosocial intervention includes six child sessions of 60 min each (once every 2 weeks) and two parent sessions (Table 1). The first element of the psychosocial intervention is psycho-education on disease-related topics. For adolescents, sexual orientation, and growth and developmental topics are added. Subsequently cognitivebehavioural components are incorporated in the program to intensify awareness of hidden feelings, thoughts, behaviour and their consequences, and to enhance coping strategies. The content of the program, psycho-educational information and assignments are standardized and compiled in an instruction manual.

To enhance the effects of the psychosocial intervention for the individual patient, the manual is divided into several modules with different topics. All topics are discussed with each patient. The number and intensity of assignments for each patient are individually tailored. The tailored program is made according to baseline information from the parents and patient, and according to the clinical evaluation of the paediatric psychologist during the intervention. Because parent support has a strong impact on a child's behaviour, two parent sessions are included to increase endurance and compliance with the QLIM intervention. The last parent session evaluates the child's functioning before and during the intervention, and the observed changes.

All patients in the intervention group are invited for a half-day booster session 3-6 months after completion of the 12-week intervention period. This booster session involves a combined group sports clinic and a psychosocial session during which participants discuss what they have learned during both elements of the QLIM intervention.

\section{Control group}

Controls are not restricted to perform activities such as school or leisure sports. Although usual care can not be standardized, it will not involve systematic exercise training or psychosocial support. However, if the patients have any physical or psychosocial problems they have access to regular health care (e.g. a physiotherapist or medical psychologist).

\section{Study outcomes \\ General}

The primary outcome of the present study is physical fitness (cardiorespiratory fitness and muscle strength). Secondary outcomes are fatigue, body composition, bone mineral density (BMD), daily physical activity, depression, HrQOL, self-perception and behaviour. Additionally, compliance and satisfaction with the intervention are evaluated by self-report; compliance is also evaluated via the therapist's report. Also assessed are potentially moderating variables (including pre-illnesses, lifestyle, health, exercise-related attitudes, beliefs and motivations) of both the child and parents.

Physical fitness is assessed by measuring both the cardiorespiratory fitness and muscle strength. BMD and fat mass are determined by a DEXA scan (lumbar spine, total body and hip) as gold standard, combined with bone markers in blood and body mass index (Table 2). Daily physical activity is assessed by wearing an Actical 2.1 accelerometer from Wednesday to Saturday on the left hip, and by keeping a physical activity diary. Fatigue, quality of life, depression, self-perception and behavioural problems are assessed by questionnaires [32-36]. In addition, the cost effectiveness of the study is determined by the use of a per month cost diary. It gathers information concerning visits to health care givers, work and school participation of both the parents and the child and performed social activities,

Table 1 Details of the Quality of Life in Motion (QLIM) psychosocial intervention

\begin{tabular}{|c|c|}
\hline $\begin{array}{l}\text { Psychosocial training } \\
\text { modules }\end{array}$ & Includes 6 child sessions and 2 parent sessions \\
\hline Session 1 ( 1 h) & $\begin{array}{l}\text { In the first module the focus is on increasing self-awareness and belief in one's own competency. During an exercise, } \\
\text { the patient is stimulated and supported to express positive things about him/herself. }\end{array}$ \\
\hline Session 2 (1 h) & $\begin{array}{l}\text { The second module focuses on feelings, thoughts, and behaviour. The central themes are the four basic feelings of a } \\
\text { human being: fear, anger, happiness and sadness. }\end{array}$ \\
\hline Session 3 (1 h) & $\begin{array}{l}\text { In the third module coping with (non) disease-related difficult situations is the main topic. Also, training in relaxation } \\
\text { exercises is given. }\end{array}$ \\
\hline Session 4 (1 h) & $\begin{array}{l}\text { The fourth module focuses on social contacts with peers. Does the disease influence their social relationships? For the } \\
\text { older age group, sexuality and relationships are also addressed. }\end{array}$ \\
\hline Session 5 (1 h) & $\begin{array}{l}\text { The fifth module focuses on possible changes in the family after the diagnosis of cancer, i.e. changes in relations with } \\
\text { siblings and parents, and separation-individuation problems. }\end{array}$ \\
\hline Session 6 (1 h) & The sixth session deals with the future and how to incorporate physical exercise in daily life from now onwards. \\
\hline Parent session 1 (1 h) & $\begin{array}{l}\text { The first parent session focuses on the principles of the program to increase parental support, in order to improve } \\
\text { compliance and endurance. }\end{array}$ \\
\hline Parent session 2 (1 h) & $\begin{array}{l}\text { The second and last parent session focuses on evaluation of the total program. Parents and therapists describe the } \\
\text { achieved goals and the changes observed during the program. }\end{array}$ \\
\hline
\end{tabular}


Table 2 Details of the primary outcome measures and the measurement tools used

\begin{tabular}{|c|c|}
\hline $\begin{array}{l}\text { Primary outcome } \\
\text { measures }\end{array}$ & Measurements \\
\hline Cardiorespiratory fitness & $\begin{array}{l}\text { Lode Corival bicycle ergometry with paediatric options; LODE BV, Groningen, the Netherlands. } \\
\text { Steep Ramp Test [35] } \\
\mathrm{VO}_{2} \text { peak performance test }\end{array}$ \\
\hline Muscle strength & CITEC hand-held dynamometer; C.I.T. Technics BV, Haren, the Netherlands \\
\hline $\begin{array}{l}\text { Secondary outcome } \\
\text { measures }\end{array}$ & Measurements \\
\hline Fatigue & PedsQL Multidimensional Fatigue Scale Acute Version (self-report and parent-proxy report) [30] \\
\hline Body composition & $\begin{array}{l}\text { Dual Energy X-ray Absorptiometry (DEXA) scan (Hologic QDR 4500); Hologic Bedford, USA. } \\
\text { Body Mass Index } \\
\text { Blood: calcium, phosphate, magnesium, carboxy-terminal collagen crosslinks (CTX), parathyroid hormone (PTH), serum } \\
\text { amino-terminal procollagen } 1 \text { extension peptide (P1NP), insulin-like growth factors } 1 \text { (IGF-1), 25-hydroxy-vitamin D } \\
\text { (25 OH vit D) }\end{array}$ \\
\hline $\begin{array}{l}\text { Daily physical activity } \\
\text { levels }\end{array}$ & Physical activity accelerometer: Actical 2.1; Respironics, Mini Mitter, Oregon USA \\
\hline Depression & Children's Depression Inventory (CDI) [32] \\
\hline Quality of life & $\begin{array}{l}\text { PedsQL 4.0 Generic Score Scale (self-report and parent-proxy report) [30] } \\
\text { PedsQL 3.0 Cancer Module (self-report and parent-proxy report) [30] }\end{array}$ \\
\hline Self-perception & $\begin{array}{l}\text { Self-Perception Profile for Children (CBSK) [31] } \\
\text { Self-Perception Profile for Adolescents (CBSA) [33] }\end{array}$ \\
\hline Behavioural problems & $\begin{array}{l}\text { Child Behavior Checklist (CBCL) [34] } \\
\text { Youth Self-Report (YSR) [34] }\end{array}$ \\
\hline Cost data & Monthly cost diary \\
\hline Other study outcomes & Measurements \\
\hline Compliance & Self-report Attendance checklist for training sessions \\
\hline $\begin{array}{l}\text { Satisfaction with the } \\
\text { intervention }\end{array}$ & Questionnaire 11-items \\
\hline Clinical data & Medical record \\
\hline Moderating variables & $\begin{array}{l}\text { Questionnaire addressing pre-illness lifestyle, current attitudes towards and beliefs about exercise, physical activity } \\
\text { patterns. }\end{array}$ \\
\hline
\end{tabular}

To facilitate comparison of results across A-CaRe studies, the outcome measures used in these four RCTs have been standardized as far as possible. A detailed description of the secondary outcome measures common to all four RCTs has been reported elsewhere [28].

All patients perform fitness tests, use an accelerometer, and complete a battery of questionnaires prior to randomization (T0), after 14-20 weeks (T1), and at 12-months follow-up (T3). At T2 (6-9 months from baseline) only the data from the questionnaires and the accelerometer data are collected.

Cardiorespiratory fitness Cardiorespiratory fitness is assessed by two $\mathrm{VO}_{2}$ peak performance tests: the Steep Ramp Test and the cardiopulmonary exercise test according to the Godfrey protocol, both on an electronically braked Lode Corival bicycle ergometer (Lode B.V., Groningen, the Netherlands). The test protocol includes one minute of rest and three minutes of cycling without resistance before the start of the Steep Ramp Test [37]. The workload at the beginning of the test is 25 watts which increases every 10 seconds by an additional 25 watts until exhaustion. The Steep Ramp test is followed by three minutes of cycling without resistance and two minutes of no movement. Following these five minutes the second test the cardiopulmonary exercise test, is introduced in which the workload increases by 10, 15 or 20 watts every minute depending on the child's body height, as described in the Godfrey protocol [38]. The patients are instructed to cycle at a speed of $60-80$ rotations per minute until he/ she stops because of volitional exhaustion. The patients breath through a facemask connected to a calibrated metabolic cart. Breath-by-breath minute ventilation, oxygen consumption, carbon dioxide production, and the respiratory exchange ratio are calculated from conventional equations. Heart rate is measured continuously during the aerobic exercise test by a bipolar electrocardiogram or heart rate monitor, as is done for the oxygen percentage by saturation measurement. $\mathrm{VO}_{2}$ peak is calculated as the average value over the last 30 seconds before subjective exhaustion.

Prior to the aerobic exercise test, pulmonary function is assessed at rest by measuring the forced air expiratory volume in $1 \mathrm{~s}$ and the forced vital capacity using a (portable) spirometer. The best out of 3 forced expiratory 
flow-volumes (in upright position) are recorded. Pulmonary function can be reliably assessed in young children [39].

Muscle strength Muscle strength of the proximal and distal muscles in the upper and lower extremities is measured by the calibrated Citec hand-held dynamometer (CIT Technics, Groningen, the Netherlands) at the right and the left side of the body. Three consecutive measurements are performed using the 'break method', in which the examiner gradually overcomes the muscle force and stops at the moment the extremity gives way [40]. The highest value of three repetitions is registered. In the upper extremity, grip strength and strength of the shoulder abductors and the elbow extensors are measured. In the lower extremity, the muscular strength of the hip flexors and the knee and dorsal foot extensors are measured. All within-subject tests are performed by the same assessor using the same hand-held dynamometer to prevent inter-instrument and interobserver bias [41]. The same assessors perform the tests in the intervention and in the control group.

\section{Characteristics of non-responders}

To compare the responders and non-responders, patients and parents not wishing to participate in the study, are asked to fill in a one-time survey regarding their reasons for non-participation, their daily physical activity, their general quality of life (PedsQL 4.0 Generic Score Scale self-report and parent-proxy report) and behavioural problems (CBCL for parents, YSR for patients aged 11 years and older). In addition, specific disease and treatment information is obtained from the patient's medical records.

\section{Power calculation}

Power calculations were performed on expected physical fitness changes. It is expected that the physical fitness of patients randomised to care as usual will deteriorate due to disease and treatment-related factors causing physical inactivity. However, it is conceivable that patients randomized to the control group are triggered to increase their normal physical activity level due to the information provided about the study. Therefore, we hypothesize that controls will maintain, rather than increase, their physical fitness during treatment since structured exercise will not be offered. In the intervention study arm, however, we expect an improvement of at least $20 \%$ in physical fitness based on data from San Juan et al. [21]. These authors found that the mean $\mathrm{VO}_{2}$ peak $(\mathrm{ml} / \mathrm{lkg} / \mathrm{min})$ at baseline increased from $24.3 \mathrm{ml} / \mathrm{lkg} / \mathrm{min}$ (SD 5.9) to $30.2 \pm 6.2 \mathrm{SD}$ following the intervention [21]. Therefore, in order to detect a $20 \%$ difference between the intervention and the control group [standard deviation difference (Cohen's effect size) 0.8 ] with a power of $80 \%$ and an alpha of 0.05 (2-sided test) at least 26 children per group are required according to the nomogram for sample size calculations [42]. The plan is to recruit 100 patients into the study to allow for an attrition of about $40 \%$ (i.e. patients who discontinue participation in the study, including failure to complete follow-up assessments). Those who discontinue participation in the intervention group, but complete the follow-up assessments, will be included in the analysis on an intention-to-treat basis. However, due to the modifications made to the 12-week exercise training program after the pilot study, we expect attrition to be significantly lower in the present study, which will significantly increase the power of the study. For intervention participants with an attrition of at least $75 \%$ a per-protocol analysis will be performed with data of the first measurement from baseline and, secondly. with data from the final measurement.

\section{Statistical analysis}

Longitudinal multi-level regression analysis is used to assess changes over time in study participants. In these, for between-group differences, the Longitudinal Generalised Estimating Equations (GEE) analysis is used. In addition, participants with at least one post-intervention assessment are analyzed according to the intention-totreat principle. Scores on the self-report measures of fatigue, quality of life, depression, self-perception and behavioural problems are calculated according to published scoring algorithms. Finally, we investigate whether compliance with the intervention is significantly associated with changes over time in physical condition, muscle strength, HrQOL and fatigue, and also determine possible determinants of effectiveness. Test results are considered significant for $\mathrm{p}$-values $<0.05$.

\section{Cost-effectiveness analysis}

This study also includes a cost-effectiveness and cost-utility analysis to determine and compare the difference in total cancer-related costs of the treatment group, and the control group. In this analysis both direct and indirect costs are taken into account. The cost-utility ratio presents the additional costs of the intervention per qualityadjusted life years (QALY); details are published in [28].

\section{Discussion}

This paper presents the design and methods of the QLIM study (A-CaRe study 4), an RCT evaluating the effect of a combined physical and psychosocial intervention on the physical fitness of children with cancer. For different chronic diseases exercise-based rehabilitation is recommended. Although this is also the case for cancer, highquality evidence for its effectiveness is lacking. The QLIM intervention is based on the theoretical framework and results from adult cancer rehabilitation studies and practice, and on pilot data from studies in children who 
survived cancer. The strength of this study is that the QLIM offers children an intervention combining both physical and psychosocial exercises. Cancer generally diminishes a child's capability to perform normal daily activities. The QLIM aims to reverse the negative self-perpetuating circle of becoming more and more inactive. The psychosocial intervention is added to improve wellbeing and thereby enhance efficacy of the exercise program. In addition to the child sessions, this psychosocial intervention includes two parent sessions to enhance parental support, which might also increase program compliance.

Due to the relatively low incidence of paediatric cancer and a mean age at diagnosis of 4 years, the number of eligible participants is relatively small. To enrol a sufficient number of patients almost all types of cancer are included, resulting in a heterogeneous study population. To ensure an equal distribution among the intervention and control group we therefore stratify for pubertal stage, type of cancer, and phase of treatment.

\section{Acknowledgements}

This study is part of the A-CaRe Program, http://www.a-care.org. The authors acknowledge the A-CaRe Clinical Research Group. The research is supported by the Alpe d'HuZes/KWF Fund. The research grant is bestowed upon the Dutch Cancer Society (grant number ALPE-VU 2009-4305), the RopaRun and the VUmc Childhood Cancer Research Foundation (VONK).

\section{Author details}

${ }^{1}$ VU University Medical Center, department of Paediatrics and Division of Oncology-Haematology, Amsterdam, the Netherlands. ${ }^{2} \mathrm{VU}$ University Medical Center, department of Medical Psychology, Amsterdam, the Netherlands. ${ }^{3}$ Wilhelmina Children's Hospital/UMC Utrecht, Paediatric Haematology/ oncology, Utrecht, the Netherlands. ${ }^{4} E m m a$ Children's Hospital/Academic Medical Centre, department of Paediatric Oncology, Amsterdam, the Netherlands. ${ }^{5}$ Emma Children's Hospital/Academic Medical Centre, Psychosocial Department, Amsterdam, the Netherlands. ${ }^{6}$ EMGO Institute for Health and Care Research, department of Public and Occupational Health, VU University Medical Center, Amsterdam, the Netherlands. ${ }^{7}$ Wilhelmina Children's Hospital/UMC Utrecht, department of Medical Psychology, Utrecht, the Netherlands. ${ }^{8}$ Wilhelmina Children's Hospital/UMC Utrecht, Child Development and Exercise Center, Utrecht, the Netherlands.

\section{Authors' contributions}

All authors contributed to the study design (with the exception of MAG and JHM who reinforced the QLIM study at a later stage). KIB and EMD are responsible for patient recruitment and data collection. KIB coordinates the logistics of the physical intervention and EMD, who developed the psychosocial intervention, coordinates the psychosocial intervention and performs the psychosocial interventions at the VU University Medical Center. Both KIB and EMD wrote the manuscript and contributed equally; GJK, JHU and TTA are principal investigators. GJK is the overall project leader. JHU leads the psychosocial content of the study; TTA developed the physical intervention and is the paediatric exercise physiology leader of the study; MAV, MBB and JHM are paediatric oncologists and clinically responsible for, respectively, the VU University Medical Center, the Wilhelmina Children's Hospital/University Medical Center Utrecht and the Emma Children's Hospital/ Academic Medical Centre, Amsterdam; GSI and MAG are responsible for the psychosocial interventions in, respectively, the Wilhelmina Children's Hospital/ University Medical Center Utrecht and the Emma Children's Hospital/ Academic Medical Centre, Amsterdam; MCP directs the four A-CaRe trials; EVD was responsible for writing the grant proposal for funding from the Dutch Cancer Society. All authors contributed to and approved the final manuscript.

\section{Competing interests}

The authors declare that they have no competing interests.

Received: 18 October 2010 Accepted: 11 November 2010 Published: 11 November 2010

\section{References}

1. Geenen MM, Cardous-Ubbink MC, Kremer LC, van den Bos C, van der Pal HJ, Heinen RC, Jaspers MW, Koning CC, Oldenburger F, Langeveld NE, Hart AA, Bakker PJ, Caron HN, van Leeuwen FE: Medical assessment of adverse health outcomes in long-term survivors of childhood cancer. JAMA 2007, 297:2705-15.

2. Warner JT, Bell W, Webb DK, Gregory JW: Daily energy expenditure and physical activity in survivors of childhood malignancy. Pediatr Res 1998, 43:607-13.

3. Van Brussel M, Takken T, Lucia A, van der Net J, Helders PJ: Is physical fitness decreased in survivors of childhood leukemia? A systematic review. Leukemia 2005, 19:13-7.

4. San Juan AF, Chamorro-Viña C, Maté-Muñoz JL, Fernández del Valle M, Cardona C, Hernández M, Madero L, Pérez M, Ramírez M, Lucia A: Functional capacity of children with leukemia. Int J Sports Med 2008, 29:163-7.

5. Aznar S, Webster AL, San Juan AF, Chamorro-Viña C, Maté-Muñoz JL, Moral S, Pérez M, García-Castro J, Ramírez M, Madero L, Lucia A: Physical activity during treatment in children with leukemia: a pilot study. App/ Physiol Nutr Metab 2006, 31:407-13.

6. Van Brussel M, Takken T, van der Net J, Engelbert RH, Bierings $M$, Schoenmakers MA, Helders PJ: Physical function and fitness in long-term survivors of childhood leukaemia. Pediatr Rehabil 2006, 9:267-74.

7. Warner JT: Body composition, exercise and energy expenditure in survivors of acute lymphoblastic leukaemia. Pediatr Blood Cancer 2008, 50:456-61.

8. Florin TA, Fryer GE, Miyoshi T, Weitzman M, Mertens AC, Hudson MM, Sklar CA, Emmons K, Hinkle A, Whitton J, Stovall M, Robison LL, Oeffinger KC: Physical inactivity in adult survivors of childhood acute lymphoblastic leukemia: a report from the childhood cancer survivor study. Cancer Epidemiol Biomarkers Prev 2007, 16:1356-63.

9. Brouwer CA, Gietema JA, Kamps WA, de Vries EG, Postma A: Changes in body composition after childhood cancer treatment: impact on future health status-a review. Crit Rev Oncol Hematol 2007, 63:32-46.

10. Tillmann V, Darlington AS, Eiser C, Bishop NJ, Davies HA: Male sex and low physical activity are associated with reduced spine bone mineral density in survivors of childhood acute lymphoblastic leukemia. J Bone Miner Res 2002, 17:1073-80.

11. Eiser C, Vance $Y H$, Horne B, Glaser A, Galvin H: The value of the PedsQLTM in assessing quality of life in survivors of childhood cancer. Child Care Health Dev 2003, 29:95-102

12. Odame I, Duckworth J, Talsma D, Beaumont L, Furlong W, Webber C, Barr R: Osteopenia physical activity and health-related quality of life in survivors of brain tumors treated in childhood. Pediatr Blood Cancer 2006, 46:357-62

13. Meeske KA, Siegel SE, Globe DR, Mack WJ, Bernstein L: Prevalence and correlates of fatigue in long-term survivors of childhood leukemia. $J$ Clin Oncol 2005, 23:5501-10.

14. Varni JW, Limbers CA, Burwinkle TM: Impaired health-related quality of life in children and adolescents with chronic conditions: a comparative analysis of 10 disease clusters and 33 disease categories/severities utilizing the PedsQL 4.0 Generic Core Scales. Health Qual Life Outcomes 2007, 5:43.

15. May AM, Van Weert E, Korstjens I, Hoekstra-Weebers JE, Van Der Schans CP, Zonderland ML, Mesters I, Van Den Borne B, Ros WD: Improved physical fitness of cancer survivors: a randomised controlled trial comparing physical training with physical and cognitive-behavioural training. Acta Oncol 2008, 47:825-34.

16. Courneya KS, Sellar CM, Stevinson C, McNeely ML, Peddle CJ, Friedenreich CM, Tankel K, Basi S, Chua N, Mazurek A, Reiman T: Randomized controlled trial of the effects of aerobic exercise on physical functioning and quality of life in lymphoma patients. J Clin Oncol 2009, 27:4605-12.

17. Weaver IC: Shaping adult phenotypes through early life environments. Birth Defects Res C Embryo Today 2009, 87:314-26. 
18. Herman KM, Hopman WM, Craig CL: Are youth BMI and physical activity associated with better or worse than expected health-related quality of life in adulthood? The Physical Activity Longitudinal Study. Qual Life Res 2010, 19:339-49.

19. Winter C, Müller C, Brandes M, Brinkmann A, Hoffmann C, Hardes J, Gosheger G, Boos J, Rosenbaum D: Level of activity in children undergoing cancer treatment. Pediatr Blood Cancer 2009, 53:438-43.

20. Ness KK, Mertens AC, Hudson MM, Wall MM, Leisenring WM, Oeffinger KC, Sklar CA, Robison LL, Gurney JG: Limitations on physical performance and daily activities among long-term survivors of childhood cancer. Ann Intern Med 2005, 143:639-47.

21. San Juan AF, Fleck SJ, Chamorro-Viña C, Maté-Muñoz JL, Moral S, Pérez M, Cardona C, Del Valle MF, Hernández M, Ramírez M, Madero L, Lucia A: Effects of an intrahospital exercise program intervention for children with leukemia. Med Sci Sports Exerc 2007, 39:13-21.

22. Hartman A, te Winkel ML, van Beek RD, de Muinck Keizer-Schrama SM, Kemper HC, Hop WC, van den Heuvel-Eibrink MM, Pieters R: A randomized trial investigating an exercise program to prevent reduction of bone mineral density and impairment of motor performance during treatment for childhood acute lymphoblastic leukemia. Pediatr Blood Cancer 2009, 53:64-71.

23. Marchese VG, Chiarello LA, Lange BJ: Effects of physical therapy intervention for children with acute lymphoblastic leukemia. Pediatr Blood Cancer 2004, 42:127-133.

24. Moyer-Mileur $\amalg$, Ransdell L, Bruggers CS: Fitness of children with standard-risk acute lymphoblastic leukemia during maintenance therapy: response to a home-based exercise and nutrition program. J Pediatr Hematol Oncol 2009, 31:259-266.

25. Dimeo FC, Stieglitz RD, Novelli-Fischer U, Fetscher S, Keul J: Effects of physical activity on the fatigue and psychologic status of cancer patients during chemotherapy. Cancer 1999, 85:2273-2277.

26. Coleman EA, Coon S, Hall-Barrow J, Richards K, Gaylor D, Stewart B: Feasibility of exercise during treatment for multiple myeloma. Cancer Nurs 2003, 26:410-9.

27. Takken $T$, van der Torre $P$, Zwerink $M$, Hulzebos EH, Bierings $M$, Helders PJM, van der Net JJ: Development, feasibility and efficacy of a community-based exercise training program in pediatric cancer survivors. Psychooncology 2009, 18:440-448.

28. Chinapaw MJ, Buffart LM, van Mechelen W, Schep G, Aaronson NK, van Harten WH, Stuiver M, Kersten MJ, Nollet F, Kaspers GJL, et al: Alpe d'HuZes Cancer Rehabilitation (A-CaRe) research. Design of four randomized controlled exercise trials in cancer patients and survivors. BMC Cancer.

29. Bradley J, Howard J, Wallace E, Elborn S: Validity of a modified shuttle test in adult cystic fibrosis. Thorax. 1999, 54:437-439.

30. Verschuren O, Takken T, Ketelaar M, Gorter JW, Helders PJ: Reliability for Running Tests for Measuring Agility and Anaerobic Muscle Power in Children and Adolescents with Cerebal Palsy. Pediatr Phys Ther 2007, 19:108-115.

31. Royal Canadian Air Force: Physical Fitness: 5BX The 11 minute exercise plan for men, XBX the 12 minute exercise plan for women London: Penguin books Ltd; 1964.

32. Varni JW, Burwinkle TM, Katz ER, Meeske K, Dickinson P: The PedsQL ${ }^{\mathrm{TM}}$ in pediatric cancer. Reliability and validity of the pediatric quality of life inventory $^{\mathrm{TM}}$ Genetic Core Scales, Multidimensional Fatigue Scale, and Cancer Module. Cancer 2002, 94:2090-2106.

33. Veerman JW, Straathof MAE, Treffers DA, van den Bergh BRH, ten Brink LT: De Competentiebelevingsschaal voor Kinderen (CBSK) Amsterdam: Harcourt Test Publishers; 2004

34. Finch AJ, Saylor CF, Edwards GL, McIntosh JA: Children's Depression Inventory: Reliability Over Repeated Administrations. J Clin Child AdolesC Psychol 1987, 16:339-341.

35. Treffers DA, Goedhardt AW, Veerman JW, van den Bergh BRH, Ackaert L, de Rycke L: Handleiding Competentie Belevingsschaal voor Adolescenten Lisse: Swets Test Publishers; 2002.

36. Verhulst FC, Koot JM, Akkerhuis GW, Veerman JW: Praktische handleiding voor de CBCL (Child behavior checklist) Assen/Maastricht: Van Gorcum; 1990.

37. De Backer IC, Schep G, Hoogeveen A, Vreugdenhil G, Kester AD, Van Breda E: Exercise testing and training in a cancer rehabilitation program: the advantage of the steep ramp test. Arch Phys Med Rehabil 2007, 88:610-616
38. Godfrey S: Exercise testing in children London: W.B. Saunders Company Ltd; 1974.

39. Liistro G, Vanwelde C, Vincken W, Vandevoorde J, Verleden G, Buffels J, COPD Advisory Board: Technical and functional assessment of 10 office spirometers: A multicenter comparative study. Chest 2006, 130:657-665.

40. Bäckman E: Methods for measurement of muscle function. Methodological aspects, reference values for children, and clinical applications. Scand J Rehabil Med Supp/ 1988, 20:9-95.

41. Sloan C: Review of the reliability and validity of myometry with children. Phys Occup Ther Pediatr 2002, 22:79-93.

42. Altman DG: Practical statistics for medical research Florida: CRC Press LLC 1999.

\section{Pre-publication history}

The pre-publication history for this paper can be accessed here: http://www.biomedcentral.com/1471-2407/10/624/prepub

doi:10.1186/1471-2407-10-624

Cite this article as: Braam et al:: Design of the Quality of Life in Motion (QLIM) study: a randomized controlled trial to evaluate the effectiveness and cost-effectiveness of a combined physical exercise and psychosocial training program to improve physical fitness in children with cancer. BMC Cancer 2010 10:624.

\section{Submit your next manuscript to BioMed Central and take full advantage of:}

- Convenient online submission

- Thorough peer review

- No space constraints or color figure charges

- Immediate publication on acceptance

- Inclusion in PubMed, CAS, Scopus and Google Scholar

- Research which is freely available for redistribution

Submit your manuscript at www.biomedcentral.com/submit
C) Biomed Central 